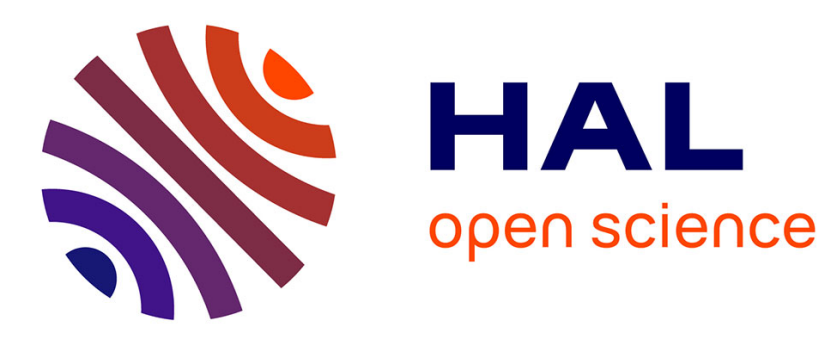

\title{
Surface mixing and biological activity in the North-West African upwelling
}

\author{
Anass El Aouni, Khalid Daoudi, Hussein Yahia, Khalid Minaoui, Aïssa \\ Benazzouz
}

\section{- To cite this version:}

Anass El Aouni, Khalid Daoudi, Hussein Yahia, Khalid Minaoui, Aïssa Benazzouz. Surface mixing and biological activity in the North-West African upwelling. Chaos: An Interdisciplinary Journal of Nonlinear Science, 2019, 29 (1), pp.011104. 10.1063/1.5067253 . hal-01985164

\section{HAL Id: hal-01985164 https://hal.inria.fr/hal-01985164}

Submitted on 17 Jan 2019

HAL is a multi-disciplinary open access archive for the deposit and dissemination of scientific research documents, whether they are published or not. The documents may come from teaching and research institutions in France or abroad, or from public or private research centers.
L'archive ouverte pluridisciplinaire HAL, est destinée au dépôt et à la diffusion de documents scientifiques de niveau recherche, publiés ou non, émanant des établissements d'enseignement et de recherche français ou étrangers, des laboratoires publics ou privés. 


\section{Surface Mixing and Biological Activity in the North-West African Upwelling}

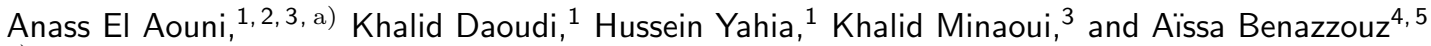

1) Geostat team, INRIA Bordeaux Sud-Ouest, 33400, Talence, France.

2) University of Bordeaux, 33000, Bordeaux, France.

3) University Mohammed V in Rabat, LRIT, 10106, Rabat, Morocco.

4) The Higher Institute of Maritime Studies, 20000, Casablanca, Morocco.

${ }^{5)}$ Faculty of sciences Ben M'Sik, BP 7955, Casablanca, Morocco.

(Dated: 14 December 2018)

Near-shore water along the North-West African margin is one of the world's major upwelling regions. It is associated with physical structures of oceanic fronts which influence the biological productivity. The study of these coherent structures in connection with chlorophyll concentration data is of fundamental importance for understanding the spatial distributions of the plankton. In this work, we study the horizontal stirring and mixing in different upwelling areas using Lagrangian coherent structures (LCSs). These LCSs are calculated using the recent geodesic theory of LCSs. We use these LCSs to study the link between the chlorophyll fronts concentrations and surface mixing, based on 10 years of satellite data. These LCSs move with the flow as material lines, thus the horizontal mixing is calculated from the intersection of these LCSs with the finite time Lyapunov exponents (FTLEs) maps. We compare our results with those of a recent study conducted over the same area, but based on Finite Size Lyapunov Exponents (FSLEs) whose output is a plot of scalar distributions. We discuss the differences between FSLE and geodesic theory of LCS. The latter yields analytical solutions of LCSs, while FSLEs can only provide LCSs for sharp enough ridges of nearly constant height.

Keywords: Horizontal Mixing and Stirring, Biological Activity, North-West African Upwelling, Hyperbolic Lagrangian Coherent Structures

Previous studies have addressed the relationship between physical structures of oceanic fronts and biological activity for a better understanding of the spatial distributions of the plankton. This relationship was investigated based on analyzing the correlation between surface mixing calculated using Finite Size Lyapunov Exponents (FSLEs), and chlorophyll concentration taken as proxy of biological productivity. However, FSLEs' output is a plot of scalar distributions, which suppose to highlight Lagrangian Coherent Structures (LCSs) that are strong indicators of fluid motion constrains. Here, in this work, we address this relationship based on a recently developed mathematically formulated coherence principles which give the exact location of LCSs. Our results shed new light on the previous studies addressing mixing using FSLEs.

\section{INTRODUCTION}

Oceanography of North-West Upwelling system is forced by the equatorward trade winds ${ }^{1,2}$. Wind-driven currents associated with equatorward trade winds are known to exhibit mesoscales instabilities ${ }^{3,4}$; thus, in addition to upwelled cold intermediate water, significant

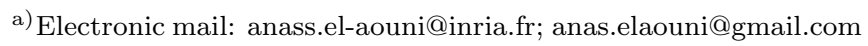

energy is transferred into submesoscale fronts and vortices in the upper ocean ${ }^{5,6}$. These submesoscale coherent structures arise out of surface frontogenesis; such frontogenesis grows off from upwelled cold filaments that are pulled offshore ${ }^{7}$. Associated with this phenomenon are large vertical vortices and material exchanges between the surface boundary layer and pycnocline ${ }^{7}$. The northeasterly winds not only drive the coastal sea surface temperature through upwelling but are also responsible for inducing the coastal baroclinic upwelling jet. This jet develops in the coastal transition zone (CTZ), located between the shelf and interior oceans ${ }^{8}$, and enables communication between adjacent latitudinal upwelling regions ${ }^{9}$. The jet constitutes the actual boundary condition of the subtropical gyre; it can be considered as the easternmost branch of the southward Canary Current, and has been named the Canary Upwelling Current (CUC) $)^{10,11}$.

Eastern Boundary Upwelling zones include some of the most productive ecosystems in the world ${ }^{1,12,13}$, particularly the North-West African upwelling which presents one of the world's major upwelling regions. North-West African upwelling is characterized by persistent and variable Upwelling phenomenon almost all around the year ${ }^{14}$. Although it represents a small portion of the world's ocean surface, it is considered as one of the most productive regions of the world ${ }^{15-18}$ due to its high biological productivity and its impact on commercial fisheries.

Mesoscales filaments and eddies structures are omnipresent in the North-West African upwelling, they interact with the complex spatial distribution of phytoplankton. These physical oceanic structures are known to affect the plankton community ${ }^{19-21}$. Indeed, they 
modulate the biomasse ${ }^{22,23}$ and play an important role in cross-shelf exchanges of water masses ${ }^{24,25}$. Moreover, their manuring role in transporting organic matter to the open ocean has been evidenced ${ }^{26}$. The study of these physical oceanic structures and their links with chlorophyll distribution are recognized as a major scientific challenge $\mathrm{e}^{27-29}$.

Much of oceanic transport is associated with coherent structures ${ }^{30}$. The development of Lagrangian diagnostics of transport is firmly gaining ground in the recent literature ${ }^{31-33}$. Such approaches come from the field of nonlinear dynamics. They are powerful tools for the identification and the analysis of oceanic transport, since they can be used to extract transport structures underlying raw Eulerian velocity data. Finite Size Lyapunov Exponents (FSLEs) are widely used in the oceanographic community, mainly for their ability to reveal and display oceanic structures that strongly organize fluid motion in the ocean; they are also used to characterize transport in closed areas and are easy to compute ${ }^{34}$. However, recent mathematically formulated Lagrangian descriptors have also found their place in the oceanographic community. ${ }^{35}$ introduces a variational principle for coherent material vortices which was applied on eddies. This method was used to study the coherent water transport off the Agulas region ${ }^{36}$. The mathematical methods were also used to study the life cycle of a coherent Lagrangian Agulhas ring ${ }^{37}{ }^{38}$ found that drifter motion in the Gulf of Mexico is constrained by altimetric Lagrangian coherent structures. ${ }^{39}$ use these Lagrangian methods to illustrate the emergence of coherent Lagrangian swirls among submesoscale motions in the ocean. They were also used to cover the edge of the polar vortex ${ }^{40}$.

In this work, we investigate the relations between horizontal mixing/stirring activity and chlorophyll concentration (considered as a proxy for biological processes). While previous studies analyze the temporal surface mix-

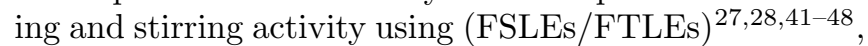
we address the problem of characterizing mixing and stirring activity, using a recent geodesic theory that allows the localization of coherent structures from mathematically formulated coherence principles ${ }^{31,49}$. We conduct an experimental study using 10 years of remotely sensed data for the period of time [2000 - 2010]; we make use of MODIS weekly chlorophyll datasets and daily interpolated velocity data derived from altimetry. We show that the use of this advanced mathematical formulation of coherence principles shed new light on previous studies about the relationships between mixing and chlorophyll.

The paper is organized as follows: section II introduces the data and the area of study used throughout this work. In section III we describe the methods used for Lagrangian Coherence Structures (LCS) calculation and chlorophyll front extraction. Section IV is devoted a presentation of experimental results. In Section V, we discuss and compare our results with state of the art. We conclude in section VI.

\section{AREA OF STUDY AND DATASET}

\section{A. Area of study}

Our work mainly focuses on zones of exchange processes between the shelf and the open ocean. Through these mesoscale processes, filament structures contribute to the offshore export of organic matter; these filament structures play consequently a fertilizing role of the adjacent oligotrophic ocean ${ }^{24,50}$. Recent work has suggested that filaments are responsible for greater offshore transport of carbon ${ }^{50-52}$.

Our study focuses on the North-West African Upwelling. We show in Fig.2 a space-time Hovmoller plot of the seasonal and interannual variability over this region of: a) the chlorophyll extension (calculated as the $0.5 m g \times m^{-3}$ limit), b) the average chlorophyll concentration (over each latitudinal step within the $0.5 \mathrm{mg} \times \mathrm{m}^{-3}$ limit) ,c) the chlorophyll index defined as the chlorophyll average multiplied by its extension, d) the eddy kinetic energy (EKE) as it is estimated from sea level anomalies from the merged mapped product AVISO using measures of Topex-Poseidon and ERS during the period 2003-2010. The Hovmoller plots show a high spatiotemporal definition of the patterns of upwelling variability in term of extension, intensity and EKE, with well defined seasonal transitions, generally associated to Capes (Cape Ghir, Cape Juby/Cape Bojdor, Cape Blanc and Cape Verde). EKE is the energy associated with fluctuations in the currents, and is a direct measure of the variability associated with eddies. Progressing south, EKE clearly increases alongshore from $0.75 \mathrm{~m}^{2} / \mathrm{s}^{2}\left(17^{\circ} \mathrm{N}\right)$ to $1 \mathrm{~m}^{2} / \mathrm{s}^{2}\left(12^{\circ} \mathrm{N}-15^{\circ} \mathrm{N}\right)$. The values of EKE in the central part of the system are among the largest in the northwest africa region coresponding to high chlrophyll index, extension and average. This is principally associated with the southward propagation of large mesoscales structures, in addition to oceanic turbulence. In this work, we mainly consider four regions with particular hydrodynamical process have been considered according to the intensity and seasonal upwelling variability and the mesoscales structures activities as depicted from satellite data and modeling approach. These four regions are listed as follow:

- 1) Cape Ghir (red box in Fig.1) located between $\left(9 .^{\circ} \mathrm{W}, 29.97^{\circ} \mathrm{N}\right.$ and $\left.13.21^{\circ} \mathrm{W}, 32.56^{\circ} \mathrm{N}\right)$ where the upwelling occurs during summer ${ }^{2}$.

- 2) The region between Cape Juby and Cape Bojador (blue box in Fig.1) located between $\left(11.91^{\circ} \mathrm{W}, 26.30^{\circ}\right.$ and $\left.16.81^{\circ} \mathrm{W}, 28 .^{\circ} \mathrm{N}\right)$ where $\max -$ imum filament intensity occurs ${ }^{53}$.

- 3) The region between the latitudes $\left(15.23^{\circ} \mathrm{W}, 19.06^{\circ}\right.$ and $20.35^{\circ} \mathrm{W}, 22.43^{\circ} \mathrm{N}$ ) (orange box in Fig.1) where the giant filament of Cape Blanco appears up to $450 \mathrm{~km}$ of extension ${ }^{54}$. 
- 4) The region with winter upwelling $^{2}$ around Cape Verde (green box in Fig.1), located between $\left(15.21^{\circ} \mathrm{W}, 13.26^{\circ}\right.$ and $\left.20.51^{\circ} \mathrm{W}, 15.87^{\circ} \mathrm{N}\right)$.

Fig.1 shows these areas delimited by colorful boxes. We use the full geographical area shown in Fig.1 for the numerical computations of the Lagrangian Coherent Structures, considering the fact that particles may get advected out of the analysis areas.

\section{B. Data}

\section{Velocity field}

We use global weekly $1 / 4^{\circ}(25 \mathrm{~km})$ resolution products of surface currents ${ }^{55}$, obtained from the Copernicus Marine Environment Monitoring Service (CMEMS ${ }^{56}$ ) and corresponding to the period of time between March 2000 to March 2010. Velocity data is derived from satellite acquired surface height (altimetry) under the geostrophic approximation, in which the sea surface height $\eta(\phi, \theta, t)$ serves as a non-canonical Hamiltonian for surface velocities in the longitude/latitude $(\phi, \theta)$ coordinate system ${ }^{57}$. From these data, daily surface currents are generated with a $0.01^{\circ}$ of spatial resolution using temporal linear interpolation ${ }^{28,58}$.

\section{Chloropyll Data}

Weekly level 3 of chlorophyll product are obtained from MODIS (Moderate Resolution Imaging Spectroradiometer) instrument operating on board the polar-orbiting Terra spacecraft. These data are generated by the NASA Goddard Earth Science (GES) and obtained from the NASA's Oceancolor website ${ }^{59}$ with a spatial resolution of $4 \times 4 \mathrm{~km}$. The data used in this study correspond to the period of time between March 2000 to March 2010 (10 years).

\section{METHOD}

The basic ingredients of our study are satellite data of chlorophyll concentration and ocean surface velocity field. We quantify the horizontal mixing processes based on the geodesic theory of Lagrangian Coherent structures $^{31,35,49}$. This theory is a collection of global variational principles for material surfaces that form the centerpieces of coherent, time-evolving tracer patterns ${ }^{31}$. Hyperbolic LCSs act as repelling or attracting neighboring material elements with locally the highest rate over a given finite-time interval. Parabolic LCSs serve as generalized jet cores. Elliptic LCSs serve as generalized coherent vortex boundaries in finite-time unsteady flows. Geodesic LCS theory is objective, and it is expressible through the invariants of the right Cauchy-Green strain

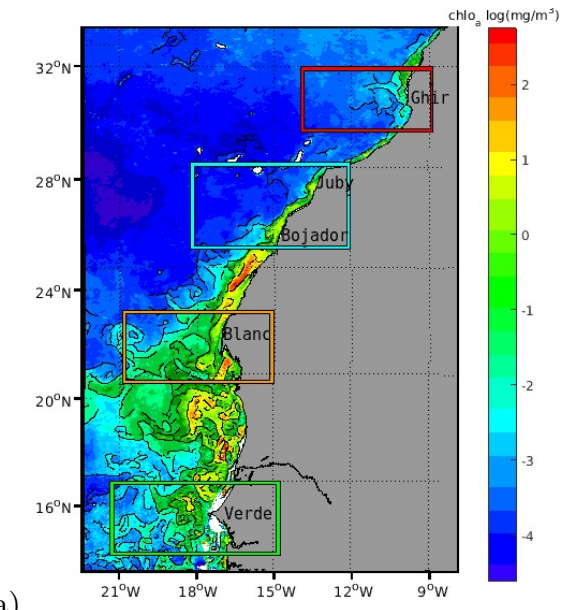

(a)

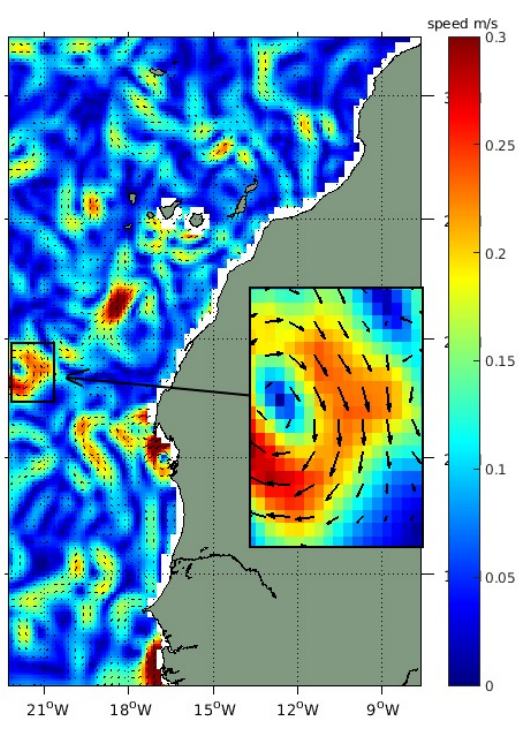

FIG. 1: a) Chlorophyll image with MSM fronts overlaid on top, b) Surface velocity and direction. Both at the same date (01-March-2003).

tensor. In this work, we calculate surface mixing based on hyperbolic (attracting) and parabolic LCSs as they have a clear interpretation as fronts of passive scalars driven by the flow ${ }^{27,31,41}$. More details are given in section 3.2.

Chlorophyll data are acquisitions of a complex natural phenomenon, with missing data and acquisition artifacts. The determination of accurate fronts in such complex natural data is challenging. For that matter, we will make use of advanced complex system approaches based on unpredictability to extract the pixels fronts in the chlorophyll datasets. This is described in the next subsection.

\section{A. Chlorophyll fronts extraction}

Chlorophyll data show coherent structures generated by oceanic turbulence. However, the datasets might contain missing data in the form of a cloud mask. The spatial 


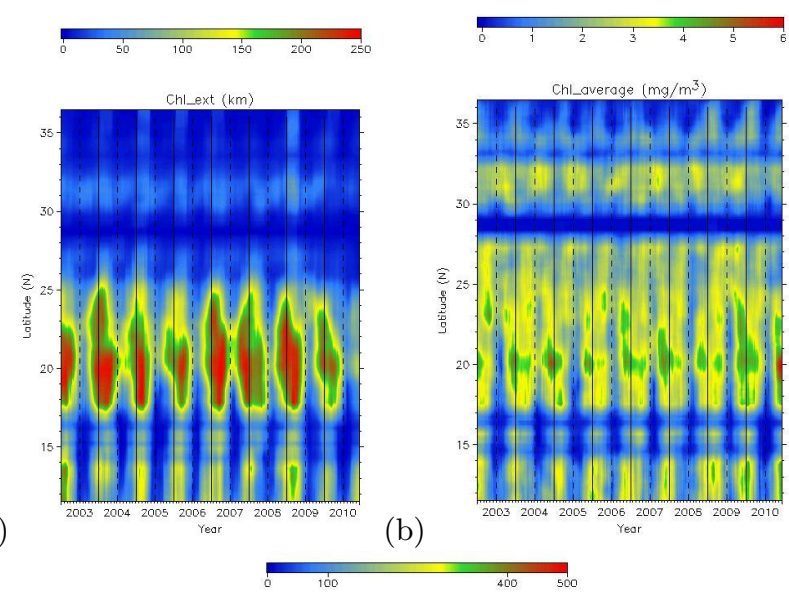

(c)
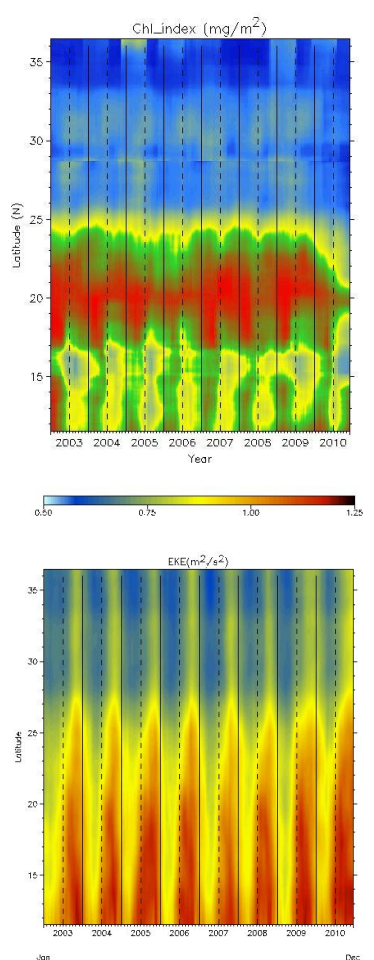

(d)

FIG. 2: Space-time Hovmoller plot of the seasonal and interannual variability a) Upwelling extension $\left(C h l_{\text {ext }}\right)$ calculated as $0.5 m g \times m^{-3}$ limit, b) Chlorophyll averaged over the Upwelling area $\left(C h l_{\text {avg }}\right)$, c) Upwelling index $\left(C h l_{i}\right)$ computed as the chlorophyll average multiplied by its extension, d) the eddy kinetic energy

(EKE) calculated for the period of time between [2003-2010].

resolution of chlorophyll data is $4 \times 4 k m$, corresponding to submesoscale. The coherent structures acquired at such resolution are the result of cascading processes associated with turbulence ${ }^{60}$. Consequently, and following the study presented in ${ }^{61}$, multiscale signal processing techniques for the extraction of pixels fronts in such data (identified as transition fronts in ${ }^{62}$ ) are more suitable than classical differential operators of image processing. In this study, we determine the pixel fronts through the calculation of singularity exponents in a microcanonical formulation of the Most Singular Manifold (MSM $)^{62}$. The singularity exponents $h(\mathbf{x})$ ( $\mathbf{x}$ is pixel location) are determined through logarithmic fitting of the chlorophyll signal's gradient.

Denoting $r_{0}$ the smallest scale in the signal, $\mu$ the measure associated to the signal's gradient, $\Psi$ a positive wavelet and $\mathcal{T}_{\Psi} \mu(\mathbf{x}, r)$ the wavelet projection of measure $\mu$ at point $\mathbf{x}$ and scale $r$, a singularity exponents $h(\mathbf{x})$ is computed as:

$$
h(\mathbf{x})=\frac{\log \mathcal{T}_{\Psi} \mu\left(\mathbf{x}, r_{0}\right) /\left\langle\mathcal{T}_{\Psi} \mu\left(0, r_{0}\right)\right\rangle}{\log r_{0}}
$$

$\langle\cdot\rangle$ denoting spatial average.

The MSM is the set

$$
\mathcal{E}_{\mathrm{MSM}}=\bigcup_{h_{\infty} \leq h \leq 0} \mathcal{F}_{h}
$$

$h_{\infty}$ being the minimal singularity exponent, $\mathcal{F}_{h}$ the set of points $\mathbf{x}$ such that $h(\mathbf{x})=h$

Practical algorithmic implementation is provided in $^{62,63}$. Once pixels fronts are extracted and MSM computed, chlorophyll concentration is calculated as the mean spatial average of chlorophyll concentration over the MSM.

\section{B. Surface Mixing and Stirring}

We consider a time-dependent smooth vector field:

$$
\mathbf{v}(\mathbf{x}, t), \quad \mathbf{x} \in \mathbb{R}^{2}, \quad t \in[\alpha, \beta]
$$

and its associated ordinary differential equation:

$$
\dot{\mathbf{x}}=\mathbf{v}(\mathbf{x}, t), \quad \mathbf{x} \in \mathbb{R}^{2}, \quad t \in[\alpha, \beta]
$$

Let $\mathbf{F}_{t_{0}}^{t}: \mathbb{R}^{2} \rightarrow \mathbb{R}^{2}$ be the associated map of the vector field $\mathbf{v}$, i.e the map which takes a particle located at $\mathbf{x}_{0}$ at time $t_{0}$ to its location $\mathbf{x}_{t}$ at time $t$ :

$$
\mathbf{F}_{t_{0}}^{t}\left(\mathbf{x}_{0}\right):=\mathbf{x}\left(t, t_{0}, \mathbf{x}_{\mathbf{0}}\right), \quad \alpha \leq t_{0} \leq t \leq \beta
$$

with $t \mapsto \mathbf{x}\left(t, t_{0}, \mathbf{x}_{0}\right)$ being the unique Lagrangian trajectory of vector field $\mathbf{v}$ which passes through $\mathbf{x}_{0}$ a time $t_{0}$. A common way to quantify the stretching is by means of the standard Lyapunov exponents such as Finite Size/Time Lyapunov Exponent (FSLE/FTLE). They are defined as the exponential rate of separation of fluid parcels infinitesimally separated at $t_{0}$ by infinitesimal perturbation $\delta \mathbf{x}_{0}:|\delta \mathbf{x}(t)| \approx e^{\lambda} \delta \mathbf{x}_{0}$. However, these exponent outputs are in the form of a scalar field, whose maxima are expected to highlight coherent structures. FSLEs ridges have been proposed as indicators of hyperbolic $\mathrm{LCSs}^{64}$. However, FSLE approach to LCSs detection is heuristic, and it is mathematically justified 
only for sharp enough FSLEs ridges of nearly constant height ${ }^{65}$. In our work we calculate the surface mixing and stirring from hyperbolic (attracting) and parabolic LCSs captured by the geodesic theory of LCS ${ }^{31}$

Let $\nabla \mathbf{F}_{t_{0}}^{t}\left(\mathbf{x}_{0}\right)$ be the Jacobian of $\mathbf{F}_{t_{0}}^{t}\left(\mathbf{x}_{0}\right)$ at location $\mathbf{x}_{0}$. Given an infinitesimal spatial perturbation $\delta \mathbf{x}\left(t_{0}\right) \in$ $\mathbb{R}^{2}$ at time $t_{0}$, the evolution of that perturbation is given by:

$$
\delta \mathbf{x}(t)=\nabla \mathbf{F}_{t_{0}}^{t}\left(\mathbf{x}_{0}\right) \delta \mathbf{x}\left(t_{0}\right)
$$

Let $\mathcal{M}\left(t_{0}\right)$ be a material line defined at time $t_{0}$, its image under Lagrangian advection at time $t$ is defined in term of the flow map as $\mathbf{F}_{t_{0}}^{t}\left(\mathcal{M}\left(t_{0}\right)\right)$. The perturbations $\delta \mathbf{x}(t)$ are related to the local deformation of $\mathbf{F}_{t_{0}}^{t}\left(\mathcal{M}\left(t_{0}\right)\right)$.

Let $\mathbf{C}_{t_{0}}^{t_{f}}\left(\mathbf{x}_{0}\right)$ be the Cauchy-Green strain tensor field

$$
\mathbf{C}_{t_{0}}^{t_{f}}\left(\mathbf{x}_{0}\right)=\left[\nabla \mathbf{F}_{t_{0}}^{t_{f}}\left(\mathbf{x}_{0}\right)\right]^{T} \nabla \mathbf{F}_{t_{0}}^{t_{f}}\left(\mathbf{x}_{0}\right)
$$

with $t_{0}$ and $t_{f}$ respectively the initial and final time, $\mathrm{T}$ denoting transposition.

$\mathbf{C}_{t_{0}}^{t_{f}}\left(\mathbf{x}_{0}\right)$ is a symmetric and positive tensor, consequently it is diagonalizable in an orthogonal basis, hence its eigenvalues $\lambda_{i}\left(\mathbf{x}_{0}\right)$ and eigenvectors $\boldsymbol{\xi}_{i}\left(\mathbf{x}_{0}\right)(i=1,2)$ satisfy:

$$
\begin{gathered}
\mathbf{C}_{t_{0}}^{t_{f}}\left(\mathbf{x}_{0}\right) \boldsymbol{\xi}_{i}\left(\mathbf{x}_{0}\right)=\lambda_{i}\left(\mathbf{x}_{0}\right) \boldsymbol{\xi}_{i}\left(\mathbf{x}_{0}\right), \quad\left|\boldsymbol{\xi}_{i}\left(\mathbf{x}_{0}\right)\right|=1, \quad i=1,2, \\
0<\lambda_{1}\left(\mathbf{x}_{0}\right)<\lambda_{2}\left(\mathbf{x}_{0}\right), \quad \boldsymbol{\xi}_{1}\left(\mathbf{x}_{0}\right) \perp \boldsymbol{\xi}_{2}\left(\mathbf{x}_{0}\right) .
\end{gathered}
$$

Moreover, in the case of incompressible flow, we have $\lambda_{1}\left(\mathbf{x}_{0}\right) \lambda_{2}\left(\mathbf{x}_{0}\right)=1^{66}$.

Shearless LCSs are a material curves whom average Lagrangian shears show no leading-order variations when comparing them to nearby $C^{1}$-close material lines. Farazmand et $a l^{49}$ show that shearless LCSs coincide with nullgeodesics of the metric tensor:

$$
D_{t_{0}}^{t_{f}}=\frac{1}{2}\left[C_{t_{0}}^{t_{f}}\left(x_{0}\right) \Omega-\Omega C_{t_{0}}^{t_{f}}\left(x_{0}\right)\right], \quad \Omega=\left(\begin{array}{cc}
0 & -1 \\
1 & 0
\end{array}\right)
$$

The tensor $D_{t_{0}}^{t_{f}}$ is Lorentzian wherever $\lambda_{1}\left(x_{0}\right) \neq$ $\lambda_{2}\left(x_{0}\right)$. All null-geodesics of $D_{t_{0}}^{t_{f}}$ are found to be trajectories of one of the two line fields.

$$
x_{0}^{\prime}=\xi_{j}\left(x_{0}\right), \quad j=1,2
$$

stretch lines are defined as trajectories of Eq.9 with $j=2$. Thus, attracting LCSs are special stretch lines that start from local minima of $\lambda_{1}\left(x_{0}\right)$.

On the other hand, parabolic LCSs, are smooth, alternating chains of shrink and stretch lines that connect tensorline singularities (more details are given $\mathrm{in}^{49}$ ).

For computing geodesic LCSs, we use the MATLAB code developed $\mathrm{in}^{67}$. We follow the trajectories of equation (4) for $T=60$ days using a standard fourth-order
Runge-Kutta scheme with an integration time step of $d t=1$ day. We use trilinear interpolation for the spatiotemporal interpolation of the velocity field. Each point of the material line $\mathcal{M}\left(t_{f}\right)$ contains the separation rate $\log \left(\lambda_{2}\left(\mathbf{x}_{0}, t_{0}, t_{f}\right)\right)$ averaged by a finite time as:

$$
\sigma=\frac{1}{2 T} \log \left(\lambda_{2}\left(\mathbf{x}_{0}, t_{0}, t_{f}\right)\right)
$$

$\sigma$ presents the FSLEs field. For each integration time step of $d t=1$ day, each point of these material lines updates its position and separation rate.

\section{Comparing FLSE to the geodesic theory of LCSs}

Finite-Size Lyapunov exponent is considered as a Lagrangian diagnostic scalar fields which has been proposed for material coherence detection in the literature. It is calculated by defining a separation time $\tau\left(x_{0} ; \delta_{0}, r\right)$ as the minimal time in which the distance between a trajectory starting from $x_{0}$ and some neighboring trajectory starting $\delta_{0}$-close to $x_{0}$ first reaches $r \delta_{0}$, with $\delta_{0}>0$ and $r>1$ are respectively the initial separation and rate of separation. Thus, FSLE is not linked directly to the flow map between times $t_{0}$ and $t_{f}$. Indeed, its scalar field includes local separation exponents for each initial condition $x_{0}$ over a different time interval of length $\tau\left(x_{0} ; \delta_{0}, r\right)$. Thus, it highlights structures arising over different time intervals.

The FLSE ridges as in indicator of LCSs is shown to be heuristic ${ }^{68}$, and only justified for sharp enough FSLE ridges of nearly constant height ${ }^{65}$. On the other hand, geodesic theory of LCSs identify the exact location of LCSs.

In term of surface mixing calculation, FLSE leaves several unaddressed issues:

- FLSE's output is a scalar field, when averaging its separation rate over a given area, we are not calculating separation rate of lines of maximum compression but also from other structures that are less of interest in this study. On the other hand, the geodesic theory of LCS guaranties that only lines of maximal convergence are included.

- FSLE structures arise from different time intervals. On the other hand, geodesic theory of LCSs extract LCSs arising over the same time interval which is move convenient an natural when comparing the surface mixing to the chlorophyll concentrations.

\section{RESULTS}

LCSs are computed for each day of the 10 years database presented in section 2.1. Following ${ }^{28}$, for each sub-region, we calculate the mixing quantity by averaging hyperbolic (attracting) and parabolic LCSs over each 
one of the boxes in Fig.1. Fig.3 shows an example of these LCSs corresponding to the time $t_{0}=$ March $01 / 2000$, with time advection $t_{f}=t_{0}-60$ days.

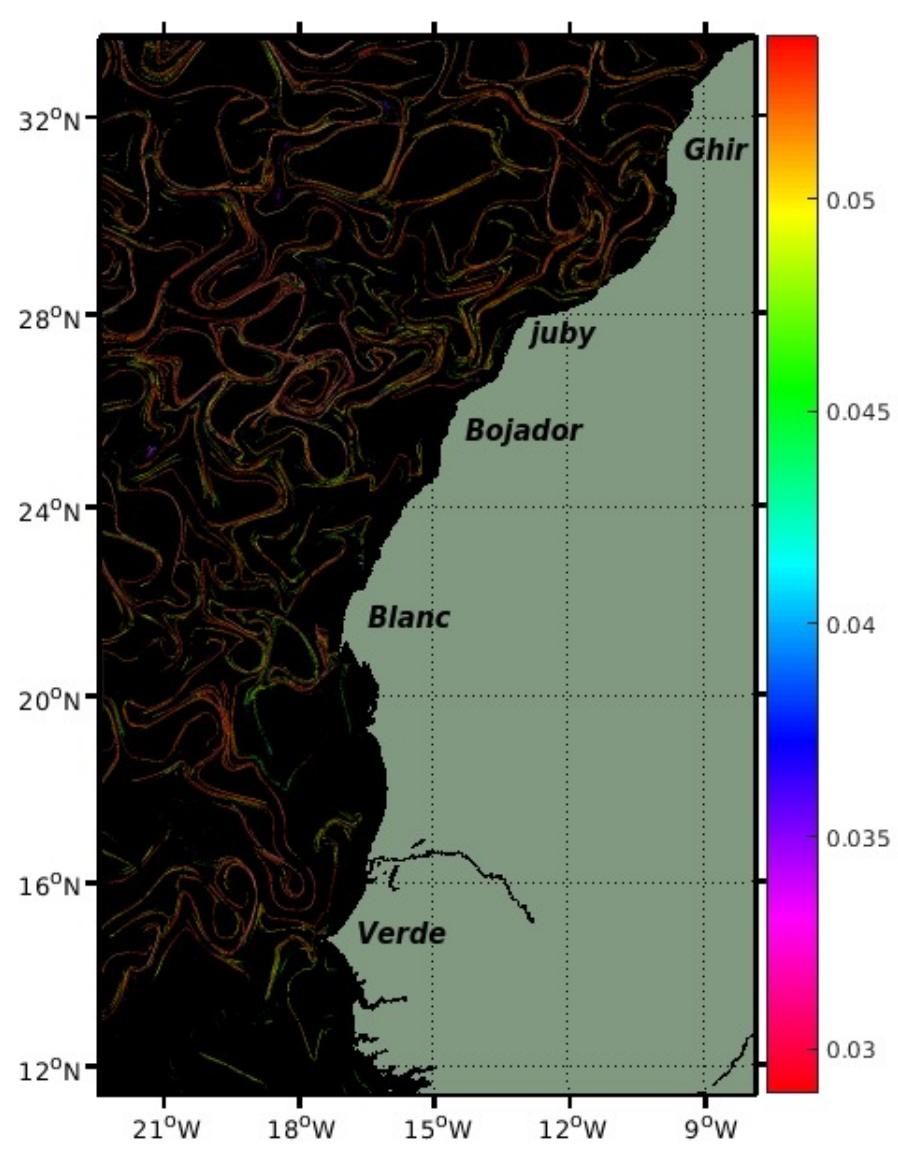

FIG. 3: Lagrangian Coherent Structures at time $t_{0}=$ March $01 / 2000$.

\section{A. Biological Activity: Surface mixing vs Chlorophyll average}

We study here the relationship between the horizontal mixing and the chlorophyll fronts concentrations. The determination of fronts is described in subsection 3.1, and we show in Fig. 1 (a) the chlorophyll fronts extracted for the date: March 01 2000. We proceed as follows: for each image, pixels fronts are extracted, then for each sub-region we compute the average of chlorophyll concentration over the set of fronts inside its corresponding box.

Fig.4 shows on each image the spatial averages of chlorophyll fronts concentration (blue color, range scale on the right) versus the spatial averages of the surface mixing (red color, range scale on the left). It is calculated from hyperbolic (attracting) and parabolic LCSs, during the period from March 01/2000 to March 01/2010.
In Cape Ghir region (red box in Fig.1), high chlorophyll concentration takes place during summer for most of the years and decreases at the end of each year. Same remark for surface mixing. Thus, both surface mixing and chlorophyll concentrations tend to have a similar interannual variation. Increase of mixing is followed by increase of chlorophyll except for 2008/2009. The period of [2003 2006] records intensity decrease of both mixing and chlorophyll.

In Cape Verde (green box in Fig.1), high mixing intensity takes place during summer for most of the years, while high chlorophyll concentration takes place during winter from 2000 till 2004, then in the summer for the rest of the years. For most of the years, increase of mixing intensity is followed by increase of chlorophyll concentration, especially for the period of [2007 2010]. Thus, both chlorophyll concentrations and mixing show similar variation for the most of the years. We note that both regions are affected by seasonal upwelling, Cape Ghir in summer (red box in Fig.1) while Cape Verde in winter (green box in Fig.1) following the seasonal movement of the Intertropical Convergence Zone ${ }^{69}$.
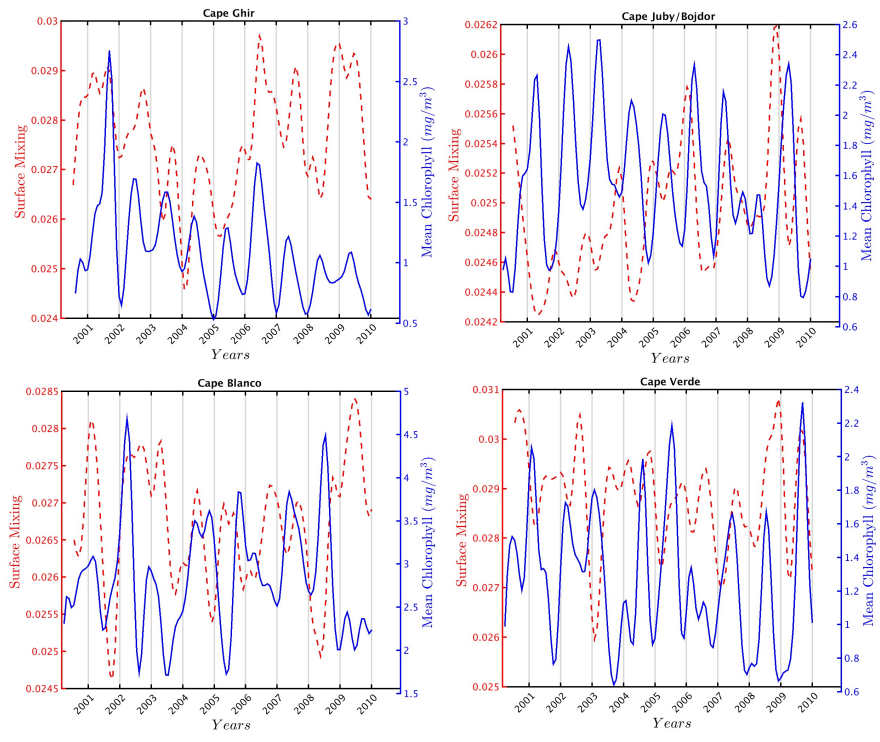

FIG. 4: Interannual variation of the surface mixing versus the fronts chlorophyll concentrations. Red axis for the mexing and the blue one is for the cholorophyll concentrations (monthly-mean).

Cape Blanco (orange box in Fig.1) with quasipermanent upwelling and highest chlorophyll concentrations (over $1.5 \mathrm{mg} / \mathrm{m}^{3}$ all over the years) shows no global significant relation between chlorophyll and surface mixing. In the period of 2000/2002, both chlorophyll and surface mixing tend to be matched, both decrease and increase in a similar way, this relation is delayed for the year 2003, and followed by negative relation starting from mid-2004.

The region between Cape Juby and Bojador (blue box in Fig.1) exhibits high chlorophyll concentration during 
summer and decreases at the end of each year. This region records no clear global relation between both chlorophyll and surface mixing. Increase of mixing is followed by decrease of chlorophyll except for the period between mid-2005 and mid-2007.

We have studied 4 areas belonging to the same upwelling ecosystem. These later show different behaviors, a region with slightly significant correlation $(r=0.58)$ and others with no significant relationship between the surface mixing and the chlorophyll concentrations. We now proceed to analyze the seasonal relationship between these two quantities.
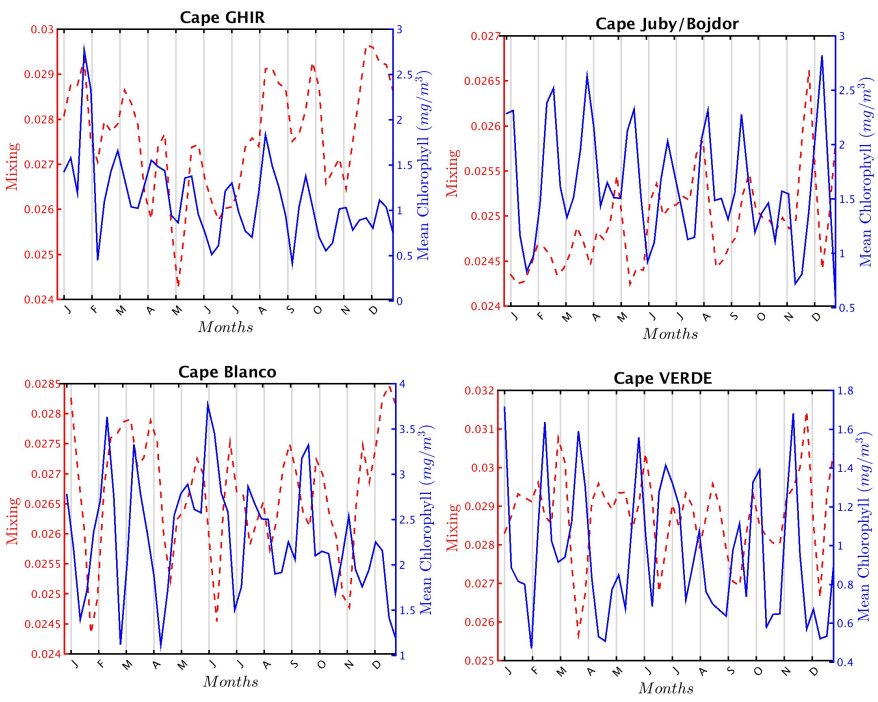

FIG. 5: Seasonal climatology of the surface mixing versus the fronts chlorophyll concentrations. Red axis for the mixing and the blue one is for the cholorophyll concentrations (monthly-mean).

Fig.5 shows on each image the seasonal climatology of chlorophyll fronts concentration (blue color, range scale on the right) versus the seasonal climatology of the mixing calculated from LCSs (red color, range scale on the left). We observe a monthly variation of the front chlorophyll concentration over the four sub-regions, as well as the mixing. Regions of Cape Ghir shows similar variations between chlo-a and mixing for most of the months. This relationship seems to changed for Cape Verde; decreasing of mixing is followed by increasing of chlorophyll concentration for the most of months. Region of Cape Blanco and region between Juby/Bojdor show no clear relation between mixing and cholrophyll concentration for most of months.

\section{B. Biological Activity: Surface mixing vs coastal jet}

Along the studied area, the winds change with the season, being upwelling favorable only from late fall to late spring when they oppose the northward flowing Mauritania Current ${ }^{70-75}$. Near Cape Blanc, the hydrodynamical process is dominated by intense coastal convergence and offshore export of coastal waters, typically not related to the local wind regime ${ }^{70,75,76}$ which explain the absent relationship between mixing and chlorophyll average in some areas. The north-easterly winds not only drive the coastal upwelling but are also responsible for inducing the coastal baroclinic upwelling jet. This jet develops in the coastal transition zone (CTZ), located between the shelf and interior oceans ${ }^{77}$, and enables communication between adjacent latitudinal upwelling regions. In some locations, the alongshore jet feeds from the interior eastern boundary ocean: input takes place between the Strait of Gibraltar and Cape Ghir, as the presence of the Strait breaks down the possibility of upstream flow ${ }^{10,78-80}$, and output occurs at the Cape Verde frontal zone (CVFZ), where the subtropical upwelled waters are diverted offshore as they encounter tropical waters from the south ${ }^{75,76}$. This can widely explain the positive correlation observed in both two areas (Cap Ghir and Cape Verde). The jet constitutes the actual boundary condition of the subtropical gyre and enhance locally the mixing of subsurface layers and consequently enhance biological productivity. Both inertia and upstream conditions introduce temporal and spatial memory to the system $^{9}$. The alongshore wind drives the alongshore coastal jet which, in turns, experiences internal friction and mixing that limits its growth. As the wind ceases or weakens, friction will progressively reduce the alongshore motion, the larger the momentum (greater inertia) the longer it will take to fully stop. It is the Coriolis force associated with the alongshore jet that induces the offshore and southward motion and mixing. Because of the coastal constraint, this offshore motion creates a crossshore pressure gradient which opposes the Coriolis force, eventually limiting the size of the cross-shore transport; the cross-shore motion will only decrease when the alongshore jet weakens. The alongshore motion is influenced by the recent history of local forcing but it is also affected by what was taking place sometime before in the neighboring areas ${ }^{81}$. As a consequence, the areas under consideration display different behaviors with slightly significant correlation (Cap Ghir and Cap Verde) and others with no significant correlation between the surface mixing and the chlorophyll concentrations (Cap Juby-Cap Blanc). Thus a further study is needed to explore the relations between chlorophyll concentrations separately with attracting LCSs repelling LCSs taking into account the importance of connections between adjacent coastal regions and between the coastal and offshore oceans. Last but not least, the upwelling vertical structure will decrease only if the winds cease all along the coast for a sufficient amount of time. Some of these ideas were endorsed by ${ }^{82}$ when they stated that upwelling depends "not just on local forcing" but on the forcing that the flow experienced "at earlier times as it moved along the coast to the region under consideration." 82 were thinking about propagating waves but the same is true for the geostrophic coastal jet. 


\section{DISCUSSION}

Hyperbolic (attracting) and parabolic LCSs, computed over 10 years from satellite velocity data derived from altimetry, allowed us to compute surface mixing and stirring of four majors areas of the North-West African Upwelling Ecosystem. According to previous studies ${ }^{22,83,84}$, meso and sub-mesoscale processes can enhance biological production in the ocean. The effect of these oceanic structures enhancing biological productivity is thought to be more pronounced in low-nutrient environments ${ }^{23,85}$. This idea of mesoscale structures generally enhancing biological productivity has been challenged by new studies suggesting that these oceanic structures could reduce primary production in the Eastern Boundary Upwelling Systems (EBUS) ${ }^{27,28,86}$. This suggestion emerged from analyzing the correlation between surface mixing calculated using FSLEs, and chlorophyll concentration taken as proxy of biological productivity.

In our work, we focused on the North-West African Upwelling. Our approach to studying the links between biological productivity and surface mixing is different from the previous ones. Instead of using the whole system as $\mathrm{in}^{28}$, we choose to divide the system into sub-regions with different upwelling properties. Our approach to calculate surface mixing differs as well from previous studies; indeed our mixing calculation is based on a mathematically formulated theory which gives the exact location of Lagrangian coherent structures. Moreover, based on the following considerations:

- There is an increasing evidence suggesting that the distribution of species at different trophic levels is influenced by this oceanic structures; most of this evidence is related to phytoplankton community ${ }^{43,48}$.

- Marine top predators are related to mesoscale fronts as well; ${ }^{47,87}$ provides evidence that top predators such us seabirds track precisely these oceanic structures to locate food patches.

Thus we choose to calculate the chlorophyll concentration only over fronts extracted from chlorophyll maps.

In this work we found that Cape Ghir which is characterized by seasonal upwelling, exhibits positive correlation between the mixing activity and the chlorophyll concentrations; this finding is in line with the suggestion of mesoscale processes enhancing biological productivity ${ }^{23,85}$. But our work challenges the finding of reducing effect due to mesoscale structures. On the other hand, ${ }^{86}$ find negative correlation between eddykinetic energy (EKE) and net primary production in the EBUS systems; this negative correlation becomes less significant in most of the EBUS systems when they are analyzed separately. We must note that here, our subregions we have tightened our studied areas to associate each area of study with specific upwelling properties (upwelling seasonality). Thus, this could explain the positive correlation found in Cape Ghir, and raise the question about how reliable is studying this relationship over the whole system at once. Another factor which may explain these results is the method used to calculate the mixing; only detects line of maximal compression; contrary to the FTLEs which produce scalar field that contains separation of maximal compressing lines and other structures of less interest. Thus the key to understand our results may lies in vertical movement: as shown in ${ }^{43}$, lines of high FSLE are more precisely located close to the vertical motions associated with eddies. ${ }^{27}$ found that regions of high FSLE indicate occurrence of vertical movements which weakens and decreases nutrients toward the surface. On the other hand, and unlike the previous studies, no significant relationship between surface mixing and chlorophyll concentration is recorded in the other regions of the studied area. An explanation to this could be the upwelling seasonality; Region of Cape blanco, Cape Juby and Bojador are affected by quasi-permanent upwelling due to the trade winds which affect these regions most of the year ${ }^{2}$, resulting in Ekman drift associated with vertical movements which dominates over other mesoscale structures; thus, nutrients of upwelled deeper water are important for sea surface fertilization in these areas.

\section{CONCLUSION}

In this work, we have used 10 years of remotely sensed velocity field derived from altimetry and chlorophyll concentrations to address the problem of the relationships between surface mixing and chlorophyll concentrations. Averaged Chlorophyll concentration is calculated from the Most Singular Manifold computed in a microcanonical formulation for fronts extraction. We have used, for the first time for this type of problem, the mathematically formulated geodesic theory of LCSs to address stirring and mixing process. Our results shed new light on the previous studies addressing mixing using FSLEs. Consequently, further work should investigate the relationship found in this upwelling ecosystem systems when examining LCSs versus production. However, the distributions of plankton community in interplay between the nonlinear processes of plankton ecology and their turbulent medium are complex. This study is in the wake of understanding the complex behaviors of the plankton community.

\section{ACKNOWLEDGEMENT}

This work is supported by the French-Moroccan PHCToubkal project $\mathrm{n}^{\circ}$ TBK/16-24 and PPR2-6 project.

\footnotetext{
${ }^{1}$ M.-E. Carr and E. J. Kearns, "Production regimes in four eastern boundary current systems," Deep Sea Research Part II: Topical Studies in Oceanography 50, 3199-3221 (2003).

${ }^{2}$ A. Benazzouz, S. Mordane, A. Orbi, M. Chagdali, K. Hilmi, A. Atillah, J. L. Pelegrí, and D. Hervé, "An improved coastal up-
} 
welling index from sea surface temperature using satellite-based approach-the case of the canary current upwelling system," Continental Shelf Research 81, 38-54 (2014).

${ }^{3} \mathrm{~J}$. Allen, "Models of wind-driven currents on the continental shelf," Annual Review of Fluid Mechanics 12, 389-433 (1980).

${ }^{4} \mathrm{H}$. Stommel, "The westward intensification of wind-driven ocean currents," Eos, Transactions American Geophysical Union 29 202-206 (1948).

${ }^{5}$ X. Capet, J. C. McWilliams, M. J. Molemaker, and A. Shchepetkin, "Mesoscale to submesoscale transition in the california current system. part ii: Frontal processes," Journal of Physical Oceanography 38, 44-64 (2008).

${ }^{6}$ X. Capet, J. C. McWilliams, M. J. Molemaker, and A. Shchepetkin, "Mesoscale to submesoscale transition in the california current system. part iii: Energy balance and flux," Journal of Physical Oceanography 38, 2256-2269 (2008).

${ }^{7}$ X. Capet, J. C. McWilliams, M. J. Molemaker, and A. Shchepetkin, "Mesoscale to submesoscale transition in the california current system. part i: Flow structure, eddy flux, and observational tests," Journal of Physical Oceanography 38, 29-43 (2008).

${ }^{8}$ E. D. Barton, "Eastern boundary of the north atlantic: northwest africa and iberia," The Sea. (1998).

${ }^{9}$ A. Benazzouz, J. L. Pelegrí, H. Demarcq, F. Machín, E. Mason, A. Orbi, J. Peña-Izquierdo, and M. Soumia, "On the temporal memory of coastal upwelling off nw africa," Journal of Geophysical Research: Oceans 119, 6356-6380 (2014).

${ }^{10}$ J. Pelegrí, J. Arístegui, L. Cana, M. González-Dávila, A. Hernández-Guerra, S. Hernández-León, A. Marrero-Díaz, M. Montero, P. Sangrà, and M. Santana-Casiano, "Coupling between the open ocean and the coastal upwelling region off northwest africa: water recirculation and offshore pumping of organic matter," Journal of Marine Systems 54, 3-37 (2005).

${ }^{11}$ J. Pelegrí, A. Marrero-Díaz, A. Ratsimandresy, A. Antoranz, J. Cisneros-Aguirre, C. Gordo, D. Grisolía, A. HernándezGuerra, I. Láiz, A. Martínez, et al., "Hydrographic cruises off northwest africa: the canary current and the cape ghir region," Journal of Marine Systems 54, 39-63 (2005).

${ }^{12}$ F. P. Chavez and M. Messié, "A comparison of eastern boundary upwelling ecosystems," Progress in Oceanography 83, 80-96 (2009).

${ }^{13}$ J. Arístegui, E. D. Barton, X. A. Álvarez-Salgado, A. M. P. Santos, F. G. Figueiras, S. Kifani, S. Hernández-León, E. Mason, E. Machú, and H. Demarcq, "Sub-regional ecosystem variability in the canary current upwelling," Progress in Oceanography 83, 33-48 (2009).

${ }^{14} \mathrm{E}$. Mittelstaedt, "The upwelling area off northwest africa-a description of phenomena related to coastal upwelling," Progress in Oceanography 12, 307-331 (1983).

${ }^{15}$ D. Pauly and V. Christensen, "Primary production required to sustain global fisheries," Nature 374, 255 (1995).

${ }^{16} \mathrm{~J}$. H. Ryther, "Photosynthesis and fish production in the sea," Science 166, 72-76 (1969).

${ }^{17}$ P. Fréon, M. Barange, and J. Aristegui, "Eastern boundary upwelling ecosystems: integrative and comparative approaches," (2009).

${ }^{18}$ D. H. Cushing, "Upwelling and the production of fish," Advances in marine biology 9, 255-334 (1971).

${ }^{19}$ D. Mackas, M. Tsurumi, M. Galbraith, and D. Yelland, "Zooplankton distribution and dynamics in a north pacific eddy of coastal origin: Ii. mechanisms of eddy colonization by and retention of offshore species," Deep Sea Research Part II: Topical Studies in Oceanography 52, 1011-1035 (2005).

${ }^{20} \mathrm{R}$. W. Owen, "Fronts and eddies in the sea: mechanisms, interactions and biological effects," Analysis of marine ecosystems , 197-233 (1981).

${ }^{21}$ J.-H. Kang, W.-S. Kim, K.-I. Chang, and J.-H. Noh, "Distribution of plankton related to the mesoscale physical structure within the surface mixed layer in the southwestern east sea, korea," Journal of plankton research 26, 1515-1528 (2004).
${ }^{22}$ D. J. McGillicuddy Jr, A. Robinson, D. Siegel, H. Jannasch, et al., "Influence of mesoscale eddies on new production in the sargasso sea," Nature 394, 263 (1998).

${ }^{23}$ A. Oschlies and V. Garcon, "Eddy-induced enhancement of primary production in a model of the north atlantic ocean," Nature 394, 266 (1998).

${ }^{24}$ A. L. Shanks and L. Brink, "Upwelling, downwelling, and crossshelf transport of bivalve larvae: test of a hypothesis," Marine Ecology Progress Series 302, 1-12 (2005).

${ }^{25}$ M. S. Dinniman, J. M. Klinck, and W. O. Smith, "Cross-shelf exchange in a model of the ross sea circulation and biogeochemistry," Deep Sea Research Part II: Topical Studies in Oceanography 50, 3103-3120 (2003).

${ }^{26}$ T. S. Moore, R. J. Matear, J. Marra, and L. Clementson, "Phytoplankton variability off the western australian coast: Mesoscale eddies and their role in cross-shelf exchange," Deep Sea Research Part II: Topical Studies in Oceanography 54, 943-960 (2007).

${ }^{27}$ V. Rossi, C. López, J. Sudre, E. Hernández-Garcia, and V. Garçon, "Comparative study of mixing and biological activity of the benguela and canary upwelling systems," Geophysical Research Letters 35 (2008).

${ }^{28}$ V. Rossi, C. López, E. Hernández-García, J. Sudre, V. Garçon, and Y. Morel, "Surface mixing and biological activity in the four eastern boundary upwelling systems," arXiv preprint arXiv:0909.0115 (2009).

${ }^{29} \mathrm{P}$. Marchesiello and P. Estrade, "Eddy activity and mixing in upwelling systems: a comparative study of northwest africa and california regions," International Journal of Earth Sciences 98, 299-308 (2009).

${ }^{30}$ J. H. Bettencourt, V. Rossi, E. Hernández-García, M. MartaAlmeida, and C. López, "Characterization of the structure and cross-shore transport properties of a coastal upwelling filament using three-dimensional finite-size lyapunov exponents," Journal of Geophysical Research: Oceans (2017).

${ }^{31}$ G. Haller, "Lagrangian coherent structures," Annual Review of Fluid Mechanics 47, 137-162 (2015).

${ }^{32}$ G. Haller and T. Sapsis, "Lagrangian coherent structures and the smallest finite-time lyapunov exponent," Chaos: An Interdisciplinary Journal of Nonlinear Science 21, 023115 (2011).

${ }^{33}$ G. Haller, "An objective definition of a vortex," Journal of fluid mechanics 525, 1-26 (2005).

${ }^{34}$ G. Károlyi, M. Pattantyús-Ábrahám, T. Krámer, J. Józsa, and T. Tél, "Finite-size lyapunov exponents: A new tool for lake dynamics," Proceedings of the Institution of Civil EngineersEngineering and Computational Mechanics 163, 251-259 (2010).

${ }^{35}$ G. Haller and F. J. Beron-Vera, "Coherent lagrangian vortices: The black holes of turbulence," Journal of Fluid Mechanics 731 (2013).

${ }^{36}$ Y. Wang, M. Olascoaga, and F. Beron-Vera, "Coherent water transport across the south atlantic," Geophysical Research Letters 42, 4072-4079 (2015).

${ }^{37}$ Y. Wang, F. Beron-Vera, and M. Olascoaga, "The life cycle of a coherent lagrangian agulhas ring," Journal of Geophysical Research: Oceans 121, 3944-3954 (2016).

${ }^{38}$ M. Olascoaga, F. Beron-Vera, G. Haller, J. Trinanes, M. Iskandarani, E. Coelho, B. Haus, H. Huntley, G. Jacobs, A. Kirwan, et al., "Drifter motion in the gulf of mexico constrained by altimetric lagrangian coherent structures," Geophysical Research Letters 40, 6171-6175 (2013).

${ }^{39}$ F. Beron-Vera, A. Hadjighasem, Q. Xia, M. Olascoaga, and G. Haller, "Coherent lagrangian swirls among submesoscale motions," Proceedings of the National Academy of Sciences , 201701392 (2018).

${ }^{40}$ M. Serra, P. Sathe, F. Beron-Vera, and G. Haller, "Uncovering the edge of the polar vortex," Journal of the Atmospheric Sciences 74, 3871-3885 (2017).

${ }^{41}$ F. d'Ovidio, V. Fernández, E. Hernández-García, and C. López, "Mixing structures in the mediterranean sea from finite-size lyapunov exponents," Geophysical Research Letters 31 (2004). 
${ }^{42}$ D. W. Waugh, S. R. Keating, and M.-L. Chen, "Diagnosing ocean stirring: Comparison of relative dispersion and finitetime lyapunov exponents," Journal of Physical Oceanography 42, 1173-1185 (2012).

${ }^{43}$ Y. Lehahn, F. d'Ovidio, M. Lévy, and E. Heifetz, "Stirring of the northeast atlantic spring bloom: A lagrangian analysis based on multisatellite data," Journal of Geophysical Research: Oceans 112 (2007).

${ }^{44} \mathrm{~J}$. Lu and K. Speer, "Topography, jets, and eddy mixing in the southern ocean," Journal of Marine Research 68, 479-502 (2010).

${ }^{45}$ J. H. Bettencourt, C. López, and E. Hernández-García, "Oceanic three-dimensional lagrangian coherent structures: A study of a mesoscale eddy in the benguela upwelling region," Ocean Modelling 51, 73-83 (2012).

${ }^{46}$ F. d'Ovidio, J. Isern-Fontanet, C. López, E. Hernández-García, and E. García-Ladona, "Comparison between eulerian diagnostics and finite-size lyapunov exponents computed from altimetry in the algerian basin," Deep Sea Research Part I: Oceanographic Research Papers 56, 15-31 (2009).

${ }^{47}$ E. T. Kai, V. Rossi, J. Sudre, H. Weimerskirch, C. Lopez, E. Hernandez-Garcia, F. Marsac, and V. Garçon, "Top marine predators track lagrangian coherent structures," Proceedings of the National Academy of Sciences 106, 8245-8250 (2009).

${ }^{48}$ F. d'Ovidio, S. De Monte, S. Alvain, Y. Dandonneau, and M. Lévy, "Fluid dynamical niches of phytoplankton types," Proceedings of the National Academy of Sciences 107, 18366-18370 (2010).

${ }^{49}$ M. Farazmand, D. Blazevski, and G. Haller, "Shearless transport barriers in unsteady two-dimensional flows and maps," Physica D: Nonlinear Phenomena 278, 44-57 (2014).

${ }^{50} \mathrm{X}$. Álvarez-Salgado, "Contribution of upwelling filaments to offshore carbon export in the subtropical northeast atlantic ocean," Limnology and Oceanography 52, 1287-1292 (2007).

${ }^{51}$ A. Cravo, P. Relvas, S. Cardeira, F. Rita, M. Madureira, and R. Sánchez, "An upwelling filament off southwest iberia: Effect on the chlorophyll a and nutrient export," Continental Shelf Research 30, 1601-1613 (2010).

${ }^{52}$ M. García-Muñoz, J. Arístegui, J. L. Pelegrí, A. Antoranz, A. Ojeda, and M. Torres, "Exchange of carbon by an upwelling filament off cape ghir (nw africa)," Journal of Marine Systems 54, 83-95 (2005).

${ }^{53}$ K. Nieto, H. Demarcq, and S. McClatchie, "Mesoscale frontal structures in the canary upwelling system: New front and filament detection algorithms applied to spatial and temporal patterns," Remote Sensing of Environment 123, 339-346 (2012).

${ }^{54}$ J. Marcello, A. Hernandez-Guerra, F. Eugenio, and A. Fonte, "Seasonal and temporal study of the northwest african upwelling system," International Journal of Remote Sensing 32, 1843-1859 (2011).

${ }^{55}$ The surface geostrophic velocities of the products we use, are the same as the ones produced by Ssalto/duacs multimission sea level products provided by CLS/Archiving, Validation, and Interpretation of Satellite Oceanographic data (AVISO), with support from CNES (http://www.aviso.oceanobs.com/duacs/).

${ }^{56} \mathrm{Http}: / /$ marine.copernicus.eu/.

${ }^{57}$ P. T. Strub and C. James, "Altimeter-derived variability of surface velocities in the california current system: 2. seasonal circulation and eddy statistics," Deep Sea Research Part II: Topical Studies in Oceanography 47, 831-870 (2000).

${ }^{58}$ G. Haller, A. Hadjighasem, M. Farazmand, and F. Huhn, "Defining coherent vortices objectively from the vorticity," Journal of Fluid Mechanics 795, 136-173 (2016).

${ }^{59}$ Https://oceancolor.gsfc.nasa.gov/.

${ }^{60}$ U. Frisch, "Turbulence (cambridge)," (1995).

${ }^{61}$ A. Turiel, H. Yahia, and C. J. Pérez-Vicente, "Microcanonical multifractal formalism - a geometrical approach to multifractal systems: Part i. singularity analysis," Journal of Physics A: Mathematical and Theoretical 41, 015501 (2008).

${ }^{62}$ S. K. Maji and H. M. Yahia, "Edges, transitions and criticality," Pattern Recognition 47, 2104-2115 (2014).
${ }^{63}$ O. Pont, A. Turiel, and H. Yahia, "Singularity analysis of digital signals through the evaluation of their unpredictable point manifold," International Journal of Computer Mathematics 90, 1693-1707 (2013).

${ }^{64} \mathrm{~B}$. Joseph and B. Legras, "Relation between kinematic boundaries, stirring, and barriers for the antarctic polar vortex," Journal of the Atmospheric Sciences 59, 1198-1212 (2002).

${ }^{65}$ D. Karrasch and G. Haller, "Do finite-size lyapunov exponents detect coherent structures?" Chaos: An Interdisciplinary Journal of Nonlinear Science 23, 043126 (2013).

${ }^{66}$ V. I. Arnol'd, Mathematical methods of classical mechanics, Vol. 60 (Springer Science \& Business Media, 2013).

${ }^{67}$ K. Onu, F. Huhn, and G. Haller, "Lcs tool: A computational platform for lagrangian coherent structures," Journal of Computational Science 7, 26-36 (2015).

${ }^{68}$ A. Hadjighasem, M. Farazmand, D. Blazevski, G. Froyland, and G. Haller, "A critical comparison of lagrangian methods for coherent structure detection," Chaos: An Interdisciplinary Journal of Nonlinear Science 27, 053104 (2017).

${ }^{69}$ W. S. Wooster, A. Bakun, and D. R. McLain, "Seasonal upwelling cycle along the eastern boundary of the north atlantic." Journal of Marine Research 34, 131-141 (1976).

${ }^{70}$ P. Castellanos, J. L. Pelegrí, and A. Benazzouz, "Wind-driven surface circulation in the cape blanc region," Continental Shelf Research 60, 87-103 (2013).

${ }^{71}$ L. Nykjær and L. Van Camp, "Seasonal and interannual variability of coastal upwelling along northwest africa and portugal from 1981 to 1991," Journal of Geophysical Research: Oceans 99, 14197-14207 (1994).

${ }^{72}$ A. Hernández-Guerra and L. Nykjaer, "Sea surface temperature variability off north-west africa: 1981-1989," International Journal of Remote Sensing 18, 2539-2558 (1997).

${ }^{73}$ H. DEMARCQ and V. FAURE, "Coastal upwelling and associated retention indices derived from satellite sst. application to octopus vulgaris recruitment," Oceanologica acta 23, 391-408 (2000).

${ }^{74}$ C. Lázaro, M. J. Fernandes, A. M. P. Santos, and P. Oliveira, "Seasonal and interannual variability of surface circulation in the cape verde region from 8 years of merged $t / p$ and ers- 2 altimeter data," Remote sensing of environment 98, 45-62 (2005).

${ }^{75}$ J. Peña-Izquierdo, J. L. Pelegrí, M. V. Pastor, P. Castellanos, M. Emelianov, M. Gasser, J. Salvador, and E. VázquezDomínguez, "The continental slope current system between cape verde and the canary islands," Scientia Marina 76, 65-78 (2012).

${ }^{76}$ M. V. Pastor, J. L. Pelegrí, A. Hernández-Guerra, J. Font, J. Salat, and M. Emelianov, "Water and nutrient fluxes off northwest africa," Continental Shelf Research 28, 915-936 (2008).

${ }^{77}$ E. Barton, J. Arıstegui, P. Tett, M. Cantón, J. GarciaBraun, S. Hernández-León, L. Nykjaer, C. Almeida, J. Almunia, $\mathrm{S}$. Ballesteros, et al., "The transition zone of the canary current upwelling region," Progress in Oceanography 41, 455-504 (1998).

${ }^{78}$ J. L. Pelegrí, A. Marrero-Díaz, and A. Ratsimandresy, "Nutrient irrigation of the north atlantic," Progress in Oceanography 70, 366-406 (2006).

${ }^{79}$ E. Mason, A. Pascual, and J. C. McWilliams, "A new sea surface height-based code for oceanic mesoscale eddy tracking," Journal of Atmospheric and Oceanic Technology 31, 1181-1188 (2014).

${ }^{80}$ R. P. Mason, A. L. Choi, W. F. Fitzgerald, C. R. Hammerschmidt, C. H. Lamborg, A. L. Soerensen, and E. M. Sunderland, "Mercury biogeochemical cycling in the ocean and policy implications," Environmental research 119, 101-117 (2012).

${ }^{81}$ A. Benazzouz, O. Mamad, P. Abedi, R. Bouali-Benazzouz, and J. Chetrit, "Involvement of dopamine loss in extrastriatal basal ganglia nuclei in the pathophysiology of parkinson's disease," Frontiers in aging neuroscience 6, 87 (2014).

${ }^{82} \mathrm{~A}$. Gill and A. Clarke, "Wind-induced upwelling, coastal currents and sea-level changes," in Deep Sea Research and Oceanographic Abstracts, Vol. 21 (Elsevier, 1974) pp. 325-345.

${ }^{83}$ P. G. Falkowski, D. Ziemann, Z. Kolber, and P. K. Bienfang, "Role of eddy pumping in enhancing primary production in the 
ocean," Nature 352, 55 (1991).

${ }^{84}$ C. R. Benitez-Nelson, R. R. Bidigare, T. D. Dickey, M. R. Landry, C. L. Leonard, S. L. Brown, F. Nencioli, Y. M. Rii, K. Maiti, J. W. Becker, et al., "Mesoscale eddies drive increased silica export in the subtropical pacific ocean," Science 316, 1017-1021 (2007).

${ }^{85}$ D. J. McGillicuddy, L. A. Anderson, N. R. Bates, T. Bibby, K. O. Buesseler, C. A. Carlson, C. S. Davis, C. Ewart, P. G. Falkowski, S. A. Goldthwait, et al., "Eddy/wind interactions stimulate extraordinary mid-ocean plankton blooms," Science 316, 1021-
1026 (2007).

${ }^{86}$ N. Gruber, Z. Lachkar, H. Frenzel, P. Marchesiello, M. Münnich, J. C. McWilliams, T. Nagai, and G.-K. Plattner, "Eddy-induced reduction of biological production in eastern boundary upwelling systems," Nature geoscience 4, 787 (2011).

${ }^{87}$ S. De Monte, C. Cotté, F. d'Ovidio, M. Lévy, M. Le Corre, and H. Weimerskirch, "Frigatebird behaviour at the oceanatmosphere interface: integrating animal behaviour with multisatellite data," Journal of the Royal Society Interface 9, 33513358 (2012). 